\title{
Is Hepatitis E a Vaccine Preventable Diseases?
}

\author{
Masoud Mardani ${ }^{1, *}$ \\ ${ }^{1}$ Infectious Diseases and Tropical Medicine Research Center, Shahid Beheshti University of Medical Sciences, Tehran, IR Iran \\ ${ }^{*}$ Corresponding author: Masoud Mardani, Infectious Diseases and Tropical Medicine Research Center, Shahid Beheshti University of Medical Sciences, Tehran, IR Iran. \\ Tel:+98-2122439963-8, E-mail: drmasoudmradani@yahoo.com
}

Received: March 5, 2015; Accepted: March 15, 2015

Keywords: Hepatitis E; Infection, Vaccines

Hepatitis E virus (HEV) is a positive-sense single-stranded RNA icosahedral virus with a 7.5 kilobase genome, which has 5 genotypes ( 1 to 5$)(1,2)$. HEV genotypes 1 and 2 are the most common causes of waterborne infections that mainly occur in resource-limited countries (3). The other pattern of transmission is from animals and humans (zoonotic transmission), caused by HEV genotype 3 or 4 and occurs widely in both resource-limited and developed countries (3). HEV infection can occur either in large epidemics in endemic regions and some parts of the Middle East or in sporadic forms in developed or developing countries $(3,4)$. HEV infection is a self-limited and clinical illness, similar to other forms of viral hepatitis except in pregnant women in whom the illness is particularly severe with a mortality rate of up to $25 \%(3,4)$. Recently, Zhang et al. reported the long-term efficacy of hepatitis E vaccine as $86.8 \%$, which is new and hopefully promising (5).

Although hepatitis $\mathrm{E}$ is known to be a problem among people living in crowded and unsanitary conditions such as camps for refugees and internally displaced people, regarding the absence of precise data, the disease and its mortality are serious problems, which make it difficult to define the clinical and public health applications of hepatitis E vaccination (6). For example, in Bangladesh, a study in which standardized interviews were conducted with family members and caregivers to assess the cause of maternal deaths revealed that one in five deaths was related to jaundice; although the published data suggested that about half of those deaths could be related to hepatitis $\mathrm{E}$ (7). If the efficacy of HEV vaccine is determined to be pan-genotypic, several public health questions must be answered, including who and when should be vaccinated, as well as the cost-effectiveness of the vaccination as a prevention tool (8). Additional data regarding the safety, immunogenicity, and efficacy of the hepatitis E vaccine in pregnant women, patients with chronic liver disease, and other vulnerable groups are needed too (8).

Before adding hepatitis E vaccination to the childhood vaccination schedule, safety and efficacy data, including its interaction with other vaccines (simultaneously) are needed in children less than 16 years of age. Also, field trial studies must be conducted to establish an effective vaccination series (9). Although studies of the vaccine suggest that 2 doses may effectively prevent hepatitis E, a well-designed evaluation of the effectiveness of fewer doses with shorter dosing schedules is required (9). The World Health Organization's Strategic Advisory Group of Experts (SAGE) on immunization recently cited the need for additional data regarding the incidence of HEV infection and disease and the safety and efficacy of the vaccine before recommending routine hepatitis $\mathrm{E}$ vaccination in countries where hepatitis $\mathrm{E}$ is highly endemic (10). Hepatitis E vaccine could become a powerful tool in the prevention and control of HEV transmission and disease. Most immediately, it can have a role in curbing outbreaks of hepatitis $\mathrm{E}$ in humanitarian crises. The benefits of broad adoption of hepatitis E vaccine can be far-reaching, if studies reveal that vaccination protects against all HEV genotypes and is safe and effective when used in people at high risk for hepatitis E-related illness and death, including pregnant women (5). In Iran, pigs and other animals have a minor role in HEV infection (11), so other measures such as preparing sanitary water for agriculture, especially vegetables, avoiding contamination of water pipelines with sources of infection, improving public awareness to preserve the hygiene of water, and enhancing epidemiological knowledge regarding HEV infection seem highly important for better application of HEV vaccine prevention program.

\section{Acknowledgements}

The author appreciates Bita Pourkaveh for collecting data.

\section{References}

1. Decard BF, Grimm A, Andelova M, Deman A, Banderet B, Garcia $\mathrm{M}$, et al. Hepatitis-E virus associated neuralgic amyotrophy with

Copyright (C) 2015, Infectious Diseases and Tropical Medicine Research Center. This is an open-access article distributed under the terms of the Creative Commons Attribution-NonCommercial 4.0 International License (http://creativecommons.org/licenses/by-nc/4.0/) which permits copy and redistribute the material just in noncommercial usages, provided the original work is properly cited. 
sustained plexus brachialis swelling visualized by high-resolution ultrasound. J Neurol Sci. 2015.

2. Tsarev SA, Binn LN, Gomatos PJ, Arthur RR, Monier MK, van CuyckGandre H, et al. Phylogenetic analysis of hepatitis E virus isolates from Egypt. J Med Virol.1999;57(1):68-74.

3. Teshale EH, Howard CM, Grytdal SP, Handzel TR, Barry V, Kamili S, et al. Hepatitis E epidemic, Uganda. Emerg Infect Dis 2010;16(1):126-9.

4. Kmush B, Wierzba T, Krain L, Nelson K, Labrique AB. Epidemiology of hepatitis E in low- and middle-income countries of Asia and Africa. Semin Liver Dis. 2013;33(1):15-29.

5. Zhang J, Zhang XF, Huang SJ, Wu T, Hu YM, Wang ZZ, et al. Long-term efficacy of a hepatitis E vaccine. $N$ Engl $J$ Med. 2015;372(10):914-22.

6. Rein DB, Stevens GA, Theaker J, Wittenborn JS, Wiersma ST. The global burden of hepatitis E virus genotypes 1 and 2 in 2005 Hepatology. 2012;55(4):988-97.

7. Gurley ES, Halder AK, Streatfield PK, Sazzad HM, Huda TM, Hossain MJ, et al. Estimating the burden of maternal and neonatal deaths associated with jaundice in Bangladesh: possible role of hepatitis E infection. Am J Public Health. 2012;102(12):2248-54.

8. Li SW, Zhao Q, Wu T, Chen S, Zhang J, Xia NS. The development of a recombinant hepatitis E vaccine HEV 239. Hum Vaccin Immunother. 2015.

9. Shrestha MP, Scott RM, Joshi DM, Mammen MJ, Thapa GB, Thapa $\mathrm{N}$, et al. Safety and efficacy of a recombinant hepatitis E vaccine. NEngl J Med. 2007;356(9):895-903.

10. World Health Organization... Available from: www.who.int.

11. Alavian SM, Fallahian F, Lankarani KB. Epidemiology of Hepatitis E in Iran and Pakistan. Hepat Mon. 2009;9(1):60-5. 